\section{Assessment of satisfaction and utilization of health-care serv- ices by National Health Insurance Scheme enrolees at Aminu Kano Teaching Hospital, Kano, Nigeria}

\author{
Abubakar Yusuf, ${ }^{1}$ Abubakar M. Jibo, ${ }^{2}$ \\ Sunusi Abubakar, ${ }^{2}$ Bukar A. Grema, ${ }^{1}$ \\ Auwal U. Gajida, ${ }^{2}$ \\ Godpower C. Michael ${ }^{1}$
}

${ }^{1}$ Family Medicine Department, ${ }^{2}$ Community Medicine Department, Aminu Kano Teaching

Hospital/Bayero University Kano, Nigeria

\begin{abstract}
The National Health Insurance Scheme (NHIS) aims at universal health coverage through access to high-quality health-care to all enrolees. To achieve this goal, it is necessary to incorporate feedbacks from periodic patient-surveys into service improvement plans. This study therefore, assessed satisfaction and utilization of health-care services by enrolees of a Nigerian tertiary hospital. This was a crosssectional study of 399 respondents randomly selected from enrolees attending the NHIS-clinic of Aminu Kano Teaching Hospital, Kano. Using an intervieweradministered questionnaire, it assessed their sociodemographics, medical history, number of and reason for clinic visits, satisfaction with- access to care, patient-provider relationships and hospital facilities/environment. Respondents' mean age was $38.3 \pm$ 9.2 years and females accounted for $55.9 \%$ of respondents. Most respondents $(60.4 \%$, $69.8 \%, 96.0 \%$ ) were satisfied with the ease of accessing care, waiting-time and hospital facilities/environment respectively. Most respondents $(94.8 \%, 81.1 \%, 73.3 \%, 74.5 \%$, $83.1 \%, 91.1 \%$ ) were satisfied with their relationship with physicians, nurses, laboratory staff, pharmacists, record officers and other hospital-staff respectively. Overall, $80.5 \%$ of respondents were satisfied with the hospital's services. All respondents had visited the clinic at least once in the preceding 12-weeks. Although 49.1\% visited for non-communicable diseases, more respondents who were for antenatal-care (followed by non-communicable and communicable diseases) had had $\geq 2$ clinic visits $\left(\mathrm{c}^{2}\right.$
\end{abstract}

$=15.5 \%, \mathrm{df}=2, \mathrm{P}=0.0001)$. This study observed a high utilization of and overallsatisfaction with the hospital's services; however, there is a need for service improvement plans to address the challenges of patient access to care and waitingtime.

\section{Introduction}

The National Health Insurance Scheme (NHIS) of Nigeria, a social health insurance scheme is a social health security system in which the health-care of an employee is paid for by both the employer and the employee. ${ }^{1}$ The scheme guarantees the provision of a benefit package of health-care services paid from funds created by pooling the contributions of participants resulting in effective sharing of health risks among participants. ${ }^{2,3}$ The main objective of the NHIS is to achieve equitable access to health-care in Nigeria towards universal health coverage (UHC); it is as an alternative source of funding for a rapidly extending and increasingly costly health-care system. ${ }^{4}$ To meet this objective, regular assessment of indicators of health system performance and quality becomes essential.

Patients' satisfaction is one of the basic objectives of healthcare service provision and often directly related to quality of services provided by healthcare providers. ${ }^{1}$ It has been defined as patients' pleasure with offered services, ${ }^{5}$ patients' feelings related to consumption of health services and its outcomes, ${ }^{6}$ and patients' feeling of pleasure or displeasure regarding the services offered by healthcare providers by comparing them with their expectations, ${ }^{7}$ which often results in consumer loyalty and retention. ${ }^{8}$ In the current competitive healthcare industry, health service quality is often rewarded by increased profit margin due to increased market share. ${ }^{9}$ Certain factors like medical staff attitude, prompt services, effective communication with patients and availability of latest, functioning equipment have been associated with patient's satisfaction. ${ }^{10}$ Furthermore, when healthcare services are not utilized, its purpose of reducing morbidity and mortality become negated. Studies have shown that commencement of health insurance increased utilization of non-urgent, and prenatal and antepartum care services in Baltimore USA and Taiwan respectively. ${ }^{11,12}$ Similarly, there was a $300 \%$ increase in service utilization between 2004 and 2011 in health insurance staff clinic in Kano following commencement of the NHIS in Nigeria. ${ }^{13}$ Health insurance reduces out-of-pocket healthcare
Correspondence: Bukar Alhaji Grema, Family Medicine Department, Aminu Kano Teaching Hospital PMB 3452, Zaria Road Kano, Nigeria

Tel.: +234.08036381118

E-mail: gremabukar@gmail.com

Key words: clinic utilization, health insurance, patient satisfaction, primary care, waiting-time.

Acknowledgements: the authors would like to thank all Clinical Assistants of Family Medicine department.

Contributions: AY, Conception, literature review, design of methodology, data collection, results/statistical analysis, manuscript preparation/editing/review and final authorization of completed; AMJ, Conception, literature review, design of methodology; SA, Results/statistical analysis, manuscript preparation/editing/review and final authorization of completed; BAG, Literature review, design of study, data/statistical, manuscript preparation/editing/review, discussions and final authorization of completed work; AUG, Manuscript preparation/editing/review and final authorization of completed; GCM, Data/statistical analysis, manuscript preparation/editing/review and final approval of completed work.

Conflict of interest: the authors declare no conflict of interest.

Funding: none.

Received for publication: 17 August 2018

Revision received: 3 Ocober 2018.

Accepted for publication: 5 Ocober 2018.

This work is licensed under a Creative Commons Attribution NonCommercial 4.0 License (CC BY-NC 4.0).

(C) Copyright A. Yusuf et al., 2018

Licensee PAGEPress, Italy

Pyramid Journal of Medicine 2018; 1:20

doi:10.4081/pjm.2018.20

expenditure however, high utilization results in long queues and prolonged waiting times. ${ }^{13,14}$ Though a previous study assessed satisfaction of enrolees of the staff clinic (a subset of the NHIS clinic) in $2015,{ }^{15}$ no study had assessed patients' satisfaction and utilization of services of the entire hospital under the NHIS. This study became necessary because of the need to incorporate feedback from periodic patient satisfaction surveys into service improvement plans of Aminu Kano Teaching Hospital - a major referral centre located in the most populous Nigerian state inhabited by over 9 million people. ${ }^{16}$ 


\section{Materials and Methods}

\section{Study area/population}

This was a descriptive cross-sectional study at the NHIS-Clinic of Aminu Kano Teaching Hospital (AKTH), Kano. Kano State lies in North-Western part of Nigeria with Kano city as its capital. AKTH is a tertiary hospital in Tarauni L.G.A. of Kano State. It is a 500 bed-capacity hospital with 17 departments including the department of Family Medicine. The NHIS Clinic is one of the clinics under the Family Medicine department (others are general outpatientand retainership clinics). The NHIS-Clinic operates from 8 a.m. to 9 p.m. from Mondays to Fridays, and from 8 a.m. to 2 p.m. on weekends and public holidays. It is run by consultant family physicians, residents in family medicine and medical officers. It also caters for primary care clients of the National Health Insurance Scheme (NHIS) and staff of the hospital. The clinic offers outpatient, antenatal, pharmacy, nursing, records, accounts services. It also has a desk office which addresses enrolees' administrative complaints and SERVICOM unit that addresses patients' rights complaints. Deserving patients are referred to the specialist clinics of the hospital. The NHIS services in Aminu Kano Teaching Hospital (AKTH) commenced in late 2005 with fortified resources which supported the existing infrastructures, equipment's and services. As at 2010, just over five thousand $(5,739)$ enrolees were enlisted under the scheme from 24 different Health Maintenance Organisations (HMOs). However, by 2015 , over thirty-three thousand $(33,313)$ enrolees were enlisted under the scheme from 38 HMOs.

The study population consisted of all adult NHIS-enrolees attending the NHISClinic of AKTH during the six-week study period (June $1^{\text {st }}$ to July $14^{\text {th }} 2016$ ).

\section{Selection criteria}

NHIS enrollees (18 years and above) who had been enrolled for at least six months before the study and who gave consent were included in the study. Enrolees who were critically ill were excluded.

\section{Sample size estimation}

The sample size was calculated using the formula: $\mathrm{n}=\mathrm{z}^{2} \mathrm{pq} / \mathrm{d}^{2},{ }^{17}$ where $\mathrm{n}=$ the desired minimum sample size (when population is $>10,000), \mathrm{z}=$ the standard normal deviate, set at 1.96 which corresponds to $95 \%$ confidence level, $\mathrm{p}=$ prevalence of health service utilization under the NHIS programme in Oyo state $=58.9 \% ;{ }^{4} \mathrm{q}=1-$ $\mathrm{p}=0.411$, and $\mathrm{d}=$ level of precision usually set at $5 \%=0.05$. Therefore, $\mathrm{n} \approx 372$ participants. Ten percent of the calculated minimum sample size (37) was added to account for possible missing or incomplete data. Thus, the study's total sample size was 409 $(372+37)$.

\section{Sampling technique}

The study's sampling frame derived from the approximately 175 adult enrolees that attend the NHIS-Clinic daily (from clinic records). This gives a total of 7350 $(175 \times 7 \times 6)$ enrolees over the six-week study period. With a sample size of 409 , the sampling interval of $1: 18(409 / 7350)$ was obtained. At registration (at the medical records unit, which registers patients for all the clinic sessions) on each day, a list of all adult patients was made in the order they were registered; from this list the first 18 patients were selected, and one (the first participant) was then picked by balloting. Subsequently, every $18^{\text {th }}$ patient on the list was selected. Where the $18^{\text {th }}$ patient did not meet inclusion criteria, the next (e.g. the $\left.19^{\text {th }}\right)$ was selected. An average of 10 participants were recruited daily until sample size was reached.

\section{Data collection}

A designed, structured, pretested questionnaire was administered by trained research assistants (medical doctors) after consent had been obtained from each participant. The questionnaire consisted of three sections viz; sociodemographic data (section 1), satisfaction with healthcare services (access to care, patient-provider relationships and hospital environment in section 2) and respondents' diagnoses on index visit (e.g. cardiovascular, diabetes mellitus, gastrointestinal and obstructive airway diseases, etc; section 3).

Respondents were considered senior cadre if they were of grade level 7 and above, whereas those with grade level below 7 were considered junior cadre. Respondents' diagnosis on the index visit was grouped into communicable diseases, non-communicable diseases and antenatal care. Satisfaction was assessed using a Likert scale scoring system. The respondents rated the satisfaction with received services into excellent (5), very good (4), good (3), fair (2) and poor (1). Responses of excellent, very good and good responses were considered satisfied whereas fair and poor were considered dissatisfied. Overall satisfaction with the hospital's services was derived from pooling the responses of excellent, very good and good across the categories of services assessed. Similarly, all responses of fair and poor were also pooled to obtain the overall dissatisfaction.
The respondents' number of hospital visits in the preceding three months were obtained from the respondents and or his/her medical records.

\section{Data management}

All data were entered in Microsoft Excel sheet and were analysed using SPSS Statistical software version 21. Categorical variables such as sex, presenting complaints, family type was reported as absolute numbers and simple percentages while continuous variables such as age, number of dependents were described using measures of central tendency (mean) and measures of dispersion (range, standard deviation) as appropriate. The chi-square test was used to assess the significance of associations between categorical variables such as the number of clinic visits and pattern of presentation, number of clinics visit and socio-demographic characteristics, pattern and determinants of utilization respectively.

\section{Ethical approval}

Ethical approval was obtained from the medical research ethics committee of AKTH. Informed consent was sought and obtained from each participant and all provisions of the Helsinki Declaration were respected.

\section{Results \\ Respondents' sociodemographic characteristics}

Of the 409 enrolees recruited, 10 provided minimal data; therefore, data for the remaining 399 respondents (representing a response rate of $97.6 \%$ ) were used for analysis. Two hundred and twenty-three respondents $(55.9 \%)$ were female. Their mean age was 38.3 years $( \pm 9.2)$, ranging from 18 to 68 years. Table 1 shows that the respondents' modal age-group was 20-44 years $(75.2 \%)$. Most respondents resided in urban areas 392 (98.2\%), were Muslims 365 $(91.5 \%)$ of the Hausa/Fulani ethnic groups $326(81.7 \%)$ and had tertiary education 240 $(60.2 \%)$. Most respondents were married 391 (98\%), although 7 (1.8\%) were single and $1(0.3 \%)$ was a widower. They were from predominantly monogamous families $322(80.7 \%) ; 214(53.6 \%)$ were principal enrolees with 167 (41.9\%) of them having 5 dependents. Most respondents 321 (80.5\%) were of the senior staff cadre.

\section{Respondents' satisfaction with healthcare services}

Table 2 shows respondents' satisfaction 
with various aspects of healthcare services at the hospital.

Easy access to care: Most respondents (60.4\%, which includes the $15.7 \%, 20.9 \%$, and $23.8 \%$ of respondents who reported excellent, very good and good respectively) were satisfied with hospital's easy access to services.

Waiting time: Most respondent (69.8\%, including the $13 \%, 21.6 \%$ and $35.2 \%$ who reported that waiting time was excellent, very good and good respectively) were satisfied respondents.

Patient-provider relationship: With respect to physicians, most respondents 378 (94.8\%) were satisfied (this comprises of $43.5 \%, 33.2 \%$ and $18.1 \%$ that selected excellent, very good and good respectively); for the nurses, $324(81.1 \%)$ respondents were satisfied (comprising 20.7\%, 29.0\% and $31.4 \%$ of respondents that selected excellent, very good and good respectively); for the laboratory staff, 292 (73.3\%) respondents were satisfied (comprising $10.7 \%, 24.4 \%$ and $38.2 \%$ that reported excellent, very good and good respectively); for pharmacists, 297 (74.5\%) respondents were satisfied (this included $17.5 \%$, $23.5 \%$ and $33.5 \%$ who selected excellent, very good and good respectively); for the record officers, $332(83.1 \%)$ respondents were satisfied (comprising 21.6\%, 30.3\% and $31.2 \%$ respondents who chose excellent, very good and good respectively); for other hospital staff, $363(91.1 \%)$ of them were satisfied (comprising 25.0\%, 38.1\% and $28.0 \%$ who selected excellent, very good and good respectively).

Hospital facilities and environment: most respondents $383(96.0 \%)$ were satisfied with the cleanliness of the hospital environment and facilities (comprising $44.4 \%, 32.8 \%$ and $18.6 \%$ who chose excellent, very good and good respectively).

\section{Overall satisfaction with services}

Table 3 shows that $321(80.5 \%)$ respon- dents was overall satisfied with the services received from the hospital, while the remaining $78(19.5 \%)$ were dissatisfied.

\section{Number of hospital visits by respon- dents}

Of the 399 respondents, $255(63.9 \%)$ had only one visit to the clinic in the preceding three-months. One hundred and forty-four (36.1\%) had two or more visits (Figure 1).

\section{Reason for hospital visit}

Most of the respondents 196 (49.1\%) had non-communicable disease as reason for index clinic visit (Figure 2). This was followed by communicable diseases in 185 (46.4\%) respondents while antenatal clinic (ANC) was reason for clinic visit in 18 $(4.5 \%)$ respondents.

\section{Relationship between number of clinic visits and reason for clinic visit}

The proportion of respondents who had at least two visits were more among women who came for antenatal clinic 64 (47.4\%) than among those for non-communicable 65 $(34.0 \%)$ and communicable diseases 15 (20.5\%) $\left[\mathrm{x}^{2}=15.5, \mathrm{P}=0.0001\right]$ (Table 4).

\section{Relationship between sociodemo- graphic variables and number of clinic visits}

Table 5 shows the relationship between respondents' sociodemographic variables and the number of clinic visits in the preceding 12 weeks. Though, more visits $(\geq 2$ visits) were made by dependents 73 $(39.5 \%)$, principal enrolees with 3 dependents 29 (43.3), senior staff 119 (37.1\%), those who took $>1$ hour to hospital 21 $(47.7 \%)$, those whose transportation cost to hospital were $>400$ (11, 50\%), and those reported that hospital services were affordable $127(36.3 \%)$, none of these sociodemographic variables were significantly associated with the number of clinic visits.
Table 1. Socio-demographic characteristics of respondents $(n=399)$.

\begin{tabular}{|c|c|c|}
\hline Characteristic & N. & Percentage \\
\hline $\begin{array}{l}\text { Age group (years) } \\
\quad<20 \\
20-44 \\
45-59 \\
\quad \geq 60\end{array}$ & $\begin{array}{c}1 \\
300 \\
93 \\
5\end{array}$ & $\begin{array}{c}0.3 \\
75.2 \\
23.3 \\
1.2\end{array}$ \\
\hline $\begin{array}{l}\text { Sex } \\
\text { Male } \\
\text { Female }\end{array}$ & $\begin{array}{l}176 \\
223\end{array}$ & $\begin{array}{l}44.1 \\
55.9\end{array}$ \\
\hline $\begin{array}{l}\text { Place of residence } \\
\text { Urban } \\
\text { Rural }\end{array}$ & $\begin{array}{c}392 \\
7\end{array}$ & $\begin{array}{c}98.2 \\
1.8\end{array}$ \\
\hline $\begin{array}{l}\text { Marital status } \\
\text { Married } \\
\text { Unmarried } \\
\end{array}$ & $\begin{array}{c}391 \\
8\end{array}$ & $\begin{array}{c}98.0 \\
2.0\end{array}$ \\
\hline $\begin{array}{l}\text { Tribe } \\
\text { Hausa/Fulani } \\
\text { Non Hausa/Fulani }\end{array}$ & $\begin{array}{c}326 \\
73\end{array}$ & $\begin{array}{l}81.7 \\
18.3\end{array}$ \\
\hline $\begin{array}{l}\text { Family type } \\
\text { Monogamous } \\
\text { Polygamous } \\
\end{array}$ & $\begin{array}{c}322 \\
77\end{array}$ & $\begin{array}{l}80.7 \\
19.3\end{array}$ \\
\hline $\begin{array}{l}\text { Religion } \\
\text { Islam } \\
\text { Christianity }\end{array}$ & $\begin{array}{c}365 \\
34\end{array}$ & $\begin{array}{c}91.5 \\
8.5\end{array}$ \\
\hline $\begin{array}{l}\text { Education } \\
\text { None } \\
\text { Quranic } \\
\text { Primary } \\
\text { Secondary } \\
\text { Tertiary } \\
\end{array}$ & $\begin{array}{c}2 \\
7 \\
28 \\
122 \\
240\end{array}$ & $\begin{array}{c}0.5 \\
1.8 \\
7.0 \\
30.6 \\
60.1 \\
\end{array}$ \\
\hline $\begin{array}{l}\text { Enrolee status } \\
\text { Principal } \\
\text { Dependant }\end{array}$ & $\begin{array}{l}214 \\
185\end{array}$ & $\begin{array}{l}53.6 \\
46.4\end{array}$ \\
\hline $\begin{array}{l}\text { Dependants in household } \\
1 \\
2 \\
3 \\
4 \\
5\end{array}$ & $\begin{array}{l}24 \\
56 \\
67 \\
85 \\
167\end{array}$ & $\begin{array}{c}6.0 \\
14.0 \\
16.8 \\
21.3 \\
41.9\end{array}$ \\
\hline $\begin{array}{l}\text { Enrolee cadre } \\
\quad \text { Junior } \\
\text { Senior }\end{array}$ & $\begin{array}{c}78 \\
321\end{array}$ & $\begin{array}{l}19.5 \\
80.5\end{array}$ \\
\hline
\end{tabular}

Table 2. Respondents 'satisfaction with different aspects of healthcare at the hospital.

\begin{tabular}{|c|c|c|c|c|c|}
\hline \multirow[t]{2}{*}{ Aspect of care } & \multicolumn{5}{|c|}{ Respondents' satisfaction } \\
\hline & Excellent n (\%) & V. good n (\%) & Good n $(\%)$ & Fair n (\%) & Poor n $(\%)$ \\
\hline Easy access to care & $377(15.7)$ & $501(20.9)$ & $570(23.8)$ & $415(17.3)$ & $531(22.2)$ \\
\hline Perception of waiting time & $260(13.0)$ & $431(21.6)$ & $702(35.2)$ & $407(20.4)$ & $195(9.8)$ \\
\hline Patient-Doctor relationship & $867(43.5)$ & $662(33.2)$ & $362(18.1)$ & $87(4.3)$ & $17(0.9)$ \\
\hline Patient-Nurse relationship & $412(20.7)$ & $579(29.0)$ & $626(31.4)$ & $275(13.8)$ & $103(5.2)$ \\
\hline Patient-Laboratory staff relationship & $213(10.7)$ & $487(24.4)$ & $762(38.2)$ & $403(20.2)$ & $130(6.5)$ \\
\hline Patient-Pharmacist relationship & $350(17.5)$ & $468(23.5)$ & $669(33.5)$ & $352(17.6)$ & $156(7.8)$ \\
\hline Patient-Record officer relationship & $431(21.6)$ & $605(30.3)$ & $622(31.2)$ & $256(12.8)$ & $81(4.1)$ \\
\hline Patient-Other staff relationship & $299(25.0)$ & $456(38.1)$ & $335(28.0)$ & $77(6.4)$ & $30(2.5)$ \\
\hline Hospital facility/ Environment & $1229(44.0)$ & $924(33.1)$ & $528(18.9)$ & $83(3.0)$ & $29(1.0)$ \\
\hline
\end{tabular}




\section{Discussion}

The overall satisfaction of patients with health-care services received at the NHIS clinic of AKTH, Kano, northwest Nigeria was high $(80.5 \%)$. This is similar to findings by Iliyasu et al. (83\%) for the entire hospital (both insured and non-insured populations), ${ }^{18}$ but was higher than reports by Ofili et al. in Benin City, south-south Nigeria $(71.8 \%),{ }^{19}$ Olusina et al. $(75 \%)^{20}$ and Eze $(53 \%)^{21}$ in Ibadan (southwest, Nigeria) and Enugu (southeast, Nigeria) respectively. Encouragingly, this result was an improvement over an earlier finding of $65.8 \%$ obtained at the Staff Clinic (a segment of the study site). ${ }^{15}$ Variations in the way services are delivered, study populations and patients' expectations could be responsible for the various satisfaction levels. Patients expectations could be affected by socio-cultural differences and variation in levels of literacy. ${ }^{22}$ The cultural milieu and relatively poor state of the local hospitals may have nullified the effect of high literacy level of our study population. High literacy level is associated higher patient expectation and lower satisfaction. ${ }^{22}$ Measuring patient satisfaction has many purposes but prominently, such interviews help to evaluate the health care services from the patient's point of view, facilitate the identification of problem areas and help generate ideas towards solving them. ${ }^{23}$

A high proportion of our respondents $(60.4 \%)$ were satisfied with the ease of accessing care from this centre. This is closely related to the $84 \%$ obtained by

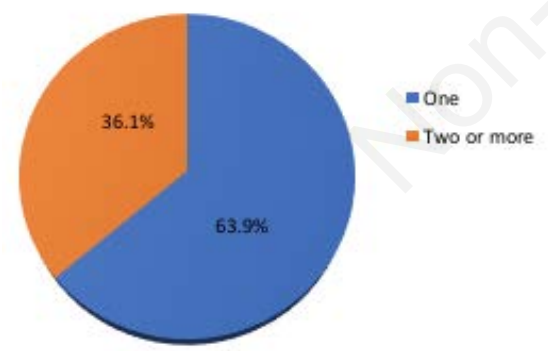

Figure 1. Number of Clinic Visits.

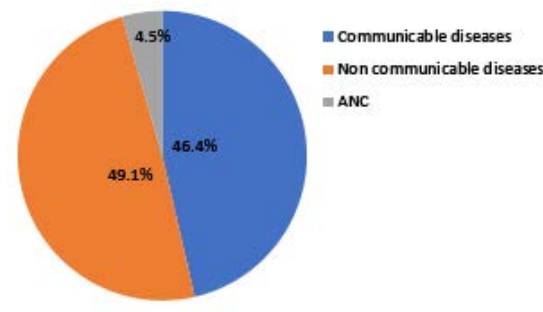

Figure 2. Reason for Clinic Visit.
Iliyasu and colleagues ${ }^{18}$ and in contrast with findings from other studies with lower proportions such as $56 \%$ in Benin City, ${ }^{19}$ $41.2 \%$ in Ibadan, ${ }^{24} 49 \%$ in Ile Ife ${ }^{25}$ and $53 \%$ in Enugu. ${ }^{21}$ In addition, our findings were in contrast with those reported in Uganda ${ }^{26}$ where only $13 \%$ of those referred to the district hospital attended because of the distance to the referral hospital. This could be because most of our study respondents lived within Kano metropolis thus making the hospital easily accessible. In addition, respondents, over time become familiar with the hospital complexity and the healthcare providers which are important determinants of increased satisfaction. ${ }^{27-29}$ However, $39.6 \%$ of our study respondents were dissatisfied. There is therefore the need for the clinic managers to investigate and address the factors associated with this level of dissatisfaction.

Patient waiting-time is often a major reason for patients' complaints in outpatient clinics. $^{30}$ Therefore, patient satisfaction with waiting-time plays a crucial role in the overall satisfaction with services. In this study, waiting-time had $30.2 \%$ of dissatisfied respondents; this proportion of dissatisfaction with waiting time may be attributed to the high clientele load of the hospital resulting in over-stretching of the personnel and facilities. Similarly, the appointment system used in many developed countries to allocate patients to different time schedules is yet to be introduced in our setting; this results in patients coming to the hospital long before opening hours and waiting for long periods before being seen. It is there- fore important to explore, even on a pilot scale, the introduction of appointment system in this clinic. This system has been shown to substantially reduce patient waiting-time at a SERVICOM pilot site at Federal Medical Centre Keffi, Nigeria. ${ }^{31}$ This study also found that a high proportion of respondents were satisfied with care provided by doctors, nurses, laboratory staffs, pharmacist, record officers and other health workers. Respondents were particularly satisfied with physician's advice and treatment, explanation and their listening abilities. Good communication between patients and care-providers has been described as the single most important components of good medical practice, not only because it identifies problems quickly and clearly, but it also defines expectation and help to establish trust between the clinician and the patient. ${ }^{27,32}$ In contrast, bad communication, particularly, when the doctor appears indifferent, unsympathetic or short of time make most patients dissatisfied. ${ }^{33}$ Good doctorpatient relationship is in itself therapeutic and successful consultation with a trusted and respected practitioner have beneficial effects irrespective of the therapy given. ${ }^{27,33}$ This might be an important reason for the high level of satisfaction with services of the clinic.

Some of the factors that attract patients to a health facility are the availability of facilities, qualified personnel and clean hospital environment. It can be responsible for recommending a hospital to friends and relatives. In this study, $95.8 \%$ of respondents were satisfied with the hospital's neatness

Table 3. Respondents' satisfaction with healthcare services $($ Total = 399).

\begin{tabular}{lcc} 
Variable & Satisfied (\%) & Dissatisfied (\%) \\
Easy access to services & $241(60.4)$ & $158(39.6)$ \\
Waiting time & $279(69.8)$ & $120(30.2)$ \\
\hline Doctor & $378(94.8)$ & $21(5.2)$ \\
Nurse & $324(81.1)$ & $75(19)$ \\
\hline Laboratory staff & $292(73.3)$ & $107(26.7)$ \\
Pharmacist & $297(74.5)$ & $102(25.4)$ \\
\hline Record officer & $332(83.1)$ & $67(16.9)$ \\
All other staff & $363(91.1)$ & $36(8.9)$ \\
\hline Hospital & $383(96.0)$ & $16(4.0)$ \\
Overall & $321(80.5)$ & $78(19.5)$
\end{tabular}

Table 4. Relationship between number of and reason for respondents' clinic visits.

\begin{tabular}{lccccc} 
Reason for visit & \multicolumn{3}{c}{ Number of visits } & \multicolumn{3}{c}{ Test statistics } \\
& $1 \mathrm{n}(\%)$ & $\geq 2 \mathrm{n}(\%)$ & Total & $\chi^{2}$ & P value \\
Communicable diseases & $58(79.5)$ & $15(20.5)$ & $73(100.0)$ & 15.5 & 0.0001 \\
Non-communicable diseases & $126(66.0)$ & $65(34.0)$ & $191(100.0)$ & & \\
\hline ANC & $71(52.6)$ & $64(47.4)$ & $135(100.0)$ & & \\
\hline
\end{tabular}


and cleanliness. This is in contrast with figures from other centres in Africa. ${ }^{24,34}$ It is however, comparable with reports by Rubin and colleague ${ }^{35}$ and Bain and colleague ${ }^{36}$ in some developed countries.

Furthermore, the pattern of health services utilization by our respondents showed that the more frequent users were women seeking for antenatal care $(47.4 \%)$. A similar finding was obtained in Taiwan where utilization of prenatal and intrapartum care rose after commencement of NHIS. ${ }^{12}$ Perceived high-standard of care in a tertiary centre like ours and high cost of antenatal and delivery services in local private hospitals may be responsible for this finding. Also, fewer respondents (34\%) with noncommunicable diseases were found among those who had $\geq 2$ clinic visits; this may be because their clinic visits are mostly based on appointment and some of them could have come with communicable diseases during the study period. In contrast, communicable diseases appeared to be more $(79.5 \%)$ among those who had only one clinic visit over the period of the study. A similar result was observed in Jordan where insurance had a positive effect on utilization of curative care and significantly increased the number of visits per illness episodes. ${ }^{37}$ In addition, health-care utilization is influenced by several factors worldwide; these include culture, age of the individual, educational level, gender, economic status, need and availability of the health care services and facilities. ${ }^{38}$ However, there were no significant associations between studied sociodemographic variables (enrolee status, number of dependents, enrolee cadre, home distance from hospital, transportation cost, service affordability) and number of clinic visits in this study; one could say that health service utilization by the respondents were based on need which conforms with the aims and objectives of the scheme. Again, all study respondents had visited the clinic in the preceding 3 -months. This is in variance with the $61.5 \%$ of respondents that utilized a segment of the NHIS-Clinic (StaffClinic) 12 -weeks before a study in $2012 ;^{13}$ this suggests an increase in the demand for health-care by the enrolees.

\section{Policy implication}

Increased utilization of the clinic should be used as an avenue for health education as this could result in reducing the risk of communicable and non-communicable diseases. There is a need to develop service improvement plans that will address the issues of waiting-time, ease in accessing care and enhance customer-care through more friendly staff attitude. Periodic patient satisfaction survey should be institutionalized to provide feedback for continuous quality improvement.

\section{Limitations of the study}

An important limitation of this study was the possibility of social desirability bias because a part of the study questionnaire depended on self-reported behaviour and perception.

\section{Conclusions}

There was a high utilization of and overall satisfaction with services of the clinic. Frequent clinic users (those with $\geq 2$ visits) were more likely to be women seeking for antenatal clinic services than non-communicable and communicable diseases. Therefore, there is a need for service improvement plans to address the challenges of patient access to care $(39.6 \%$ of respondents were dissatisfied), waiting time

Table 5. Relationship between respondents' sociodemographics and number of clinic visits.

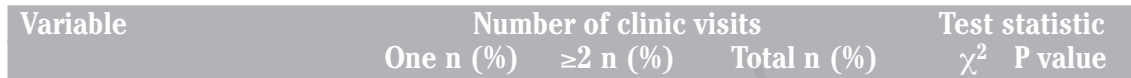

\begin{tabular}{lccccc} 
Religion & & & & \\
$\quad$ Islam & $236(64.7)$ & $129(35.3)$ & $365(100.0)$ & 1.0 & 0.3 \\
Christianity & $19(55.9)$ & $15(44.1)$ & $34(100.0)$ & & \\
Gender & $119(67.6)$ & $57(32.4)$ & $176(100.0)$ & 1.9 & 0.2 \\
$\quad$ Male & $136(61.0)$ & $87(39.0)$ & $223(100.0)$ & & \\
Female & & & & & \\
\hline Place of residence & $246(63.2)$ & $143(36.8)$ & $389(100.0)$ & FT* & 0.4 \\
$\quad$ Urban & $6(85.7)$ & $1(14.3)$ & $7(100.0)$ & & \\
$\quad$ Rural & $247(63.3)$ & $143(36.7)$ & $390(100.0)$ & & 0.2 \\
Marital status & $8(88.9)$ & $1(11.1)$ & $9(100.0)$ & & \\
$\quad$ Married & $211(64.7)$ & $115(35.3)$ & $326(100.0)$ & 0.5 & 0.5 \\
$\quad$ Not married & $44(60.3)$ & $29(39.7)$ & $73(100.0)$ & & \\
Tribe & $199(61.8)$ & $123(38.2)$ & $322(100.0)$ & 2.3 & 0.1 \\
$\quad$ Hausa/Fulani & $56(72.7)$ & $21(27.3)$ & $77(100.0)$ & & \\
$\quad$ Non-Hausa/Fulani & & & & \\
Family type & & & & \\
$\quad$ Monogamous & Polygamous & & & & \\
\hline
\end{tabular}

\begin{tabular}{lccccc}
\hline Education & & & & \\
Informal & $7(77.8)$ & $2(22.2)$ & $9(100.0)$ & 1.9 & 0.6
\end{tabular}

Primary $\quad 18(64.3) \quad 10(35.7) \quad 28(100.0)$

Secondary $\quad 73(59.8) \quad 49(40.2) \quad 122(100.0)$

$\begin{array}{llll}\text { Tertiary } & 157(65.4) & 83(34.6) & 240(100.0)\end{array}$

\begin{tabular}{llllll} 
Enrolee status & & & & \\
Principal & $143(66.8)$ & $71(33.2)$ & $214(100.0)$ & 1.7 & 0.2 \\
Dependent & $112(60.5)$ & $73(39.5)$ & $185(100.0)$ & & \\
\hline
\end{tabular}

Dependents in household

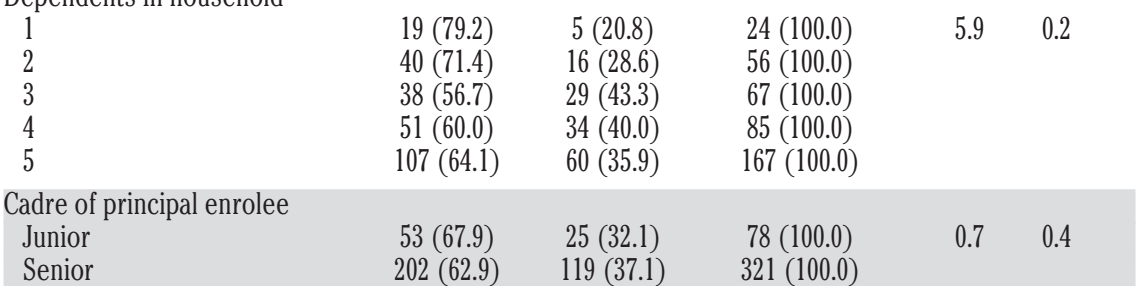

Home to hospital time

\begin{tabular}{lccccc}
$\leq 1$ hour & $232(65.4)$ & $123(34.6)$ & $355(100.0)$ & 2.9 & 0.1 \\
$>1$ hour & $23(52.3)$ & $21(47.7)$ & $44(100.0)$ & & \\
$\begin{array}{l}\text { Cost of transportation } \\
\leq \$ 400\end{array}$ & $244(64.7)$ & $133(35.3)$ & $377(100.0)$ & 2.0 & 0.2 \\
$>$ >400 & $11(50.0)$ & $11(50.0)$ & $22(100.0)$ & & \\
\hline Affordability & & & & & \\
$\quad$ Affordable & $223(63.7)$ & $127(36.3)$ & $350(100.0)$ & 0.05 & 0.8 \\
$\quad$ Not affordable & $32(65.3)$ & $17(34.7)$ & $32(100.0)$ & & \\
\hline
\end{tabular}

*Fisher exact tes 
(30.2\% were dissatisfied), and increased utilization towards improving the proportion of satisfied enrolees.

\section{References}

1. Woodside AG, Frey LL, Daly RT. Linking service quality, customer satisfaction and behavioural intention. J Health Care Market 1999;9:5-17.

2. Ekman B. The impact of health insurance on outpatient utilization and expenditure: evidence from one middleincome country using national household survey data. Health Res Policy Syst 2007;5:6.

3. Folland S, Goodman AC, Stano M. The economics of health and health care. 4 th ed. Pearson Prentice Hall: Upper Saddle River NJ; 2004. p. 520-24.

4. Sanusi A, Awe AT. An assessment of awareness level of national health insurance among healthcare consumers in Oyo state, Nigeria. Medwell J 2009; 4:143-8.

5. Sixma HJ, Spreeuwenberg PM, Van der pasch MA. Patient satisfaction with general practitioner: a two-level analysis. Medical Care 1998;36:212-29.

6. Parasuraman A, Leonard B, Zeithaml V. Measurement and evaluation of satisfaction process in retail setting. J Retailing 1981;57:25-48.

7. Kotler P. Marketing management. 5th ed. Pearson Education, Inc; 2003.

8. Calnan M. Towards a conceptual framework of lay evaluation of health care. Soc Sci Med 1998;27:927-33.

9. Devlin SI, Dong HK. Service quality from customers' perspective. Market Res 1994;6:5-13.

10. Peprah AA. Determinants of patients' satisfaction at Sunyani regional hospital, Ghana. Int J Business Soc Res 2014;4:96-108.

11. Speck SK, Peyrot M, Hsaw CW. Insurance coverage and health care consumers' use of emergency departments: has managed care made a difference? J Hosp Mark Publ Relat 2003;15:3-18.

12. Luo X, Liu G, Frush K, Hey LA. Children's health insurance status and emergency department utilization in the United States. Paediatrics 2003;112: 314-9.

13. Michael GC, Grema BA, Yakubu SO, Aliyu I. Utilization of staff clinic facility in a Northwest Nigeria hospital: emerging challenges for the National Health Insurance Scheme. South Afr Fam Pract 2016;58:37-41

14. Bruce E, Narh-Bana S, Agyepong I. Community satisfaction, equity in coverage and implementation for sustainability of the Dangme West health insurance scheme. Ghana Dutch Colabor Health Res Dev 2008;5:98106.

15. Michael GC, Suleiman HH, Grema BA, Aliyu I. Assessment of level of satisfaction of national health insurance scheme enrolees with services of an accredited health facility in Northern Nigerian. Ann Trop Med Public Health 2017;10:1271-7.

16. National Population Commission. 2006. Final Census Results. National Population Commission of Nigeria. 2009. Available from: http://www.popuation.gov.ng/index.php/statepopulation

17. Araoye MO. Sample Size Determination. Research Methodology with Statistics for Health and Social Sciences. 2nd ed. Ilorin: Nathadex Publishers; 2004. p. 115-20.

18. Iliyasu Z, Abubakar IS, Abubakar S, et al. Patients' satisfaction with services obtained from Aminu Kano Teaching Hospital, Kano, Northern Nigeria. Nig J Clin Pract 2010;13:371-8.

19. Ofili AN, Ofovwe CE. Patients' assessment of efficiency services at a teaching hospital in a developing country. Ann Afr Med 2005;4:150-3.

20. Olusina AK, Ohaeri JU, Olatawa MO. Patients' and staff satisfaction with the quality of in-patient psychiatric care in a Nigerian general hospital. Soc Psychiatr Psychiatr Epidemiol 2004;37:283-8.

21. Eze CU. Survey of patient satisfaction with obstetric ultrasound at University of Nigeria Teaching Hospital Enugu, Nigeria. Niger J Health Biomed Sci 2006;5:93-7.

22. Linder-Pelz S. Toward a theory of patient satisfaction. Soc Sci Med 1982;16:577-82.

23. Sitzia J, Wood N. Patient satisfaction: a review of issues and concepts. Soc Sci Med 1997;45:1829-43.

24. Olumide EAA, Ajayi IO. Are patients safe and satisfied? Proceedings of the national conference on primary health care in Nigeria: the journey so far. Federal Ministry of Health, Abuja 1999; 1:31-32.

25. Afolabi MO, Erhun WO. Patients' response to waiting time in an outpatient pharmacy in Nigeria. Trop J Pharm Res 2003;2:207-14.

26. Whitworth J, Pickering H, Mulwanyi F, et al. Determinants of attendance and patient satisfaction at eye clinics south western Uganda. Health Policy Plan 1999; 14:77-81.

27. Reeder LG. The patient-client as a consumer: Some observations on the changing professional-client relationship. J Health Soc Behav 1972;13:40612.

28. Ware JE, Snyder MR, Wright R. Defining and measuring patient satisfaction with medical care. Eval Prog Plan 1983;6:247-63.

29. Hulka BS, Zyzanski SJ, Cassel JC, Thompson JS. Scale for measurement of attitude towards physicians and primary medical care. Med Care 1970;8:429-36.

30. Adamu H, Oche MO. Patient satisfaction with services at a general outpatient clinic of a tertiary hospital in Nigeria. Br J Med Med Res 2014;4:2182-202.

31. SERVICOM. Evaluation reports. Available from http://www.servenigeria.com. [Accessed 2015/5/14].

32. Wilson P, McNamara JR. How perceptions of a simulated physician-patient interaction influence intended satisfaction and compliance. Soc Sci Med 1982;16:1699-1704.

33. Bush T, Cherkin D, Barlow. The impact of physician attitudes on patient satisfaction with care for low back pain. Arch Fam Med 1993;2:301-5.

34. Zein A. Operational study of the outpatient department at the public health hospital at Gondar, Ethiopia. Ethiop Med J 1978;16:45-52

35. Ashitey GA, Wurpa FK, Belcehr DW. Donfa rural health center: its patients and services. Ghana Med J 1972;11: 266-273.

36. Rubin HR, Ware JE, Hays RD. The patient judgements of hospital quality (PJHQ) questionnaire. Med Care 1990;28:522-9.

37. Bain J, Kelly H, Snadden D, Staines H. Day surgery in Scotland: patient satisfaction and outcomes. Qual Health Care 1999;8:86-91.

38. Jehu-Appiah C, Aryeetey G, Agyepong I, et al. Household perceptions and their implications for enrolment in the national health insurance scheme in Ghana. Health Policy Plan 2011;27: 222-33. 